\title{
Avaliação de um Jogo Educativo para o Desenvolvimento do Pensamento Computacional na Educação Infantil
}

\author{
Tancicleide C. S. Gomes ${ }^{1}$, Pedro Pires Barreto ${ }^{1}$, Isabella Rocha Albuquerque \\ Lima $^{1}$, Taciana Pontual Falcão ${ }^{1}$ \\ ${ }^{1}$ Departamento de Estatística e Informática - Universidade Federal Rural de \\ Pernambuco - Recife - PE - Brasil \\ tancigomes@bsi.ufrpe.net, pedropiresb@gmail.com, \\ isabellaral@gmail.com, tacianapontual@gmail.com
}

\begin{abstract}
Digital games have been increasingly present in educational contexts and their intrinsic characteristics emerge as innovative possibilities to present content in a more attractive and motivating way. This article presents an evaluation of an educational game for teaching computational thinking, from two perspectives: formative and objective evaluation. The results show that the game can be an adequate possibility for teaching computational thinking, but the assistance of a teacher is necessary.
\end{abstract}

Resumo. Os jogos digitais têm estado cada vez mais presentes nos contextos educacionais, e suas características intrínsecas despontam como possibilidades inovadoras para apresentar conteúdos de maneira mais atraente e motivadora. O presente artigo versa sobre a avaliação de um jogo educativo para o ensino do pensamento computacional sob dois vieses: o da avaliação formativa e o da avaliação objetiva. Os resultados demonstram que o jogo pode ser uma possibilidade adequada para o ensino do pensamento computacional, mas se faz necessário o acompanhamento de um professor.

\section{Introdução}

É notável o crescimento na utilização de tecnologias como computadores e internet na sociedade contemporânea. O uso dessas tecnologias tem transformado as relações humanas em todos os setores, inclusive no setor educacional, de modo que os arranjos educativos em que a transmissão de conhecimento acontecia apenas do professor para $o$ aluno tem passado por profundas rupturas e os computadores estão cada vez mais presentes na sala de aula, transformando todo o processo educativo e descentralizando a obtenção do conhecimento.

Segundo Schneider (2002) estas transformações são necessárias no atual paradigma da educação pois a interatividade é muito importante para manter a atenção dos estudantes. Os jogos, por sua vez, têm como um de seus principais atrativos a interatividade e surgem como ferramentas complementares que têm galgado um alcance cada vez maior no processo educativo.

Von Wangenheim e Von Wangenheim (2012) afirmam que os jogos proporcionam um ambiente que fomenta a experimentação e inclui a visualização das consequências dos erros cometidos, permitindo que o estudante possa aprender na prática, além de obter um feedback instantâneo e customizado de acordo com sua performance. Os jogos educativos, em específico, podem ser definidos como jogos que possuem uma proposta pedagógica inserida em seu conteúdo e contribuem para que o 
processo de ensino-aprendizagem ocorra de forma mais natural, prazerosa e dinâmica [Nicoletti e Filho 2004]. A partir deste cenário, e considerando as possibilidades oferecidas pelos jogos digitais que favorecem a motivação, o entretenimento e a ludicidade, emerge a busca por jogos educativos adequados para auxiliar no desenvolvimento do pensamento computacional, que Von Wangenheim et al. (2014) definem como:

\section{[...]uma abordagem para a resolução de problemas de forma que pode ser implementada com um computador, usando um conjunto de conceitos, tais como abstração, recursão e iteração, processamento, análise de dados e criação de artefatos reais e virtuais. [...]}

Neste sentido, este artigo apresenta a avaliação de um jogo educacional voltado ao desenvolvimento do pensamento computacional na educação infantil (The Foos), a partir de duas abordagens: objetiva e formativa.

] O objetivo desse artigo é apresentar uma ampla avaliação deste software educativo, englobando desde critérios de ergonomia e usabilidade, até mesmo aspecto didático-pedagógicos. O jogo The Foos e os métodos utilizados para a sua avaliação são introduzidos nas duas próximas seções. Em seguida, os resultados obtidos são exibidos e discutidos. E, na seção seguinte, são apresentadas as considerações finais, bem como possibilidades para trabalhos futuros.

\section{O Jogo The Foos}

The Foos $^{l}$ consiste em um jogo criado para auxiliar na disseminação do pensamento computacional para crianças a partir dos cinco anos de idade. Nele, o jogador deve guiar os personagens para realizar pequenas tarefas, e à medida que o jogador avança de fase, novos recursos e botões de comando são introduzidos.

Os movimentos do personagem são realizados através de blocos de instruções drag-and-drop que representam ações como: andar, pular, capturar um objeto, lançar um objeto; e mesmo instruções algorítmicas mais sofisticadas como laços e condicionais, além de comandos extras para personagens específicos. Os blocos instruções devem ser arrastados até o painel de execução e a execução pode ser acionada tocando no personagem. No momento em que um novo comando é necessário para realizar uma tarefa, a imagem de uma mão induz o jogador a utilizar os novos blocos e/ou parâmetros, tocando-os e arrastando-os até o painel de execução.

A cada oito fases concluídas, uma fase bônus é liberada. Esta fase consiste em um espaço para exploração criativa em que a criança pode inserir ou remover personagens e determinar blocos de instruções para controlar a interação entre eles e os elementos ao redor, sem a necessidade de resolução de uma tarefa específica. The Foos está disponível gratuitamente para os sistemas operacionais Android, iOS e Kindle, e para computadores é possível realizar o download na Mac App Store ou jogar no browser diretamente no site. Para computadores com Windows só é possível jogar através do navegador web. Alguns recursos adicionais direcionados aos professores estão disponíveis no site oficial, como o Teachers Guide, que contém a resolução dos primeiros 24 níveis. Já o Curriculum contém o currículo proposto, assim como um breve plano de ensino.

\footnotetext{
${ }^{1} \mathrm{http}: / /$ thefoos.com/
} 
CBIE-LACLO 2015

Anais dos Workshops do IV Congresso Brasileiro de Informática na Educação (CBIE 2015)

\section{Metodologia}

A utilização de um modelo de avaliação é importante para definir em que situação o jogo educativo deve ser utilizado, demonstrar o que o jogo será capaz de proporcionar para o aluno, e se o jogo é adequado para um processo educacional. Essa avaliação deve ser feita de maneira criteriosa, pois a escolha de um jogo educativo inadequado pode ter um resultado negativo no processo de aprendizagem.

Segundo Gladcheft et al. (2001), não se pode avaliar um software educacional apenas com base nas características de qualidade técnicas, tais como funcionalidade, usabilidade, confiabilidade, eficiência, manutenabilidade e portabilidade. Portanto, a avaliação da qualidade para software educacional deve ser elaborada não apenas com base nas características técnicas de qualidade, o que define a avaliação objetiva, mas também nas características ligadas ao processo educacional, o que está intimamente ligado à abordagem formativa da avaliação [Oliveira 2001].

A primeira abordagem possui diversos parâmetros técnicos que são avaliados e classificados de alguma forma por pessoas com conhecimentos sobre os mesmos. A abordagem formativa, por sua vez, considera as reações dos usuários durante e depois do uso do jogo a ser analisado, as quais podem ser coletadas através da técnica de observação.

\subsection{Avaliação Objetiva}

$\mathrm{Na}$ avaliação objetiva é necessária a especificação dos critérios de avaliação do sistema, os quais abordam diversos parâmetros. A fim de realizar a avaliação objetiva neste trabalho foi compilado um conjunto de parâmetros para avaliar jogos educacionais. Para nortear a criação deste conjunto de critérios, foram utilizados alguns modelos de avaliação.

O método que mais forneceu critérios para a avaliação objetiva aqui proposta foi o desenvolvido por Reeves. De acordo com Reeves apud Campos (1989), para avaliar um software é necessário abordar duas perspectivas: pedagógica e análise de interface. Além desse método, foram utilizados critérios dos modelos de Mucchielli [Brito Junior 2014, Nesbit, Belfer e Leacock 2002, Rocha 1987]. Após análise dos métodos, foram selecionados 10 critérios considerados pelos autores como importantes para avaliar um jogo educacional, a saber:

- Facilidade de uso: analisa a interação do usuário com o sistema e o número de erros cometidos durante esta interação;

- Design da tela: observa a riqueza no layout, considerando, por exemplo, se o jogo educacional traz fontes fáceis de reconhecer;

- Apresentação da informação: facilidade de encontrar as informações básicas do jogo como ajuda, configurações, próximas ações e objetivos;

- Afetividade: considera se o jogo proporciona um ambiente agradável, com elementos conectados ao mundo infantil, que possam criar laços emocionais entre os alunos e o jogo;

- Motivação: potencial de motivar o interesse, vontade, desejo e esforço dos usuários;

- Objetividade: analisa a maneira na qual são dispostas as metas do jogo ao usuário, bem como a apresentação geral do software; 


\section{CBIE-LACLO 2015}

Anais dos Workshops do IV Congresso Brasileiro de Informática na Educação (CBIE 2015)

- Papel do instrutor: observa o papel do instrutor no uso do jogo educacional, se provedor de materiais ou agente facilitador. No primeiro caso, o instrutor é considerado o detentor do conhecimento, enquanto no segundo ele é visto como uma fonte de orientação e consulta;

- Estruturação: o jogo pode ser classificado como altamente estruturado, quando sua sequência/ seus caminhos já foram determinados previamente; ou com baixa estruturação, quando o aluno pode escolher a ordem que desejar para seguir ao longo do jogo;

- Controle do aluno: avalia a possibilidade do usuário controlar o encadeamento e realização das ações.

- Aprendizado cooperativo: verifica se o jogo estimula o trabalho em equipe e a cooperação em algumas partes ou de forma integral, fazendo com que os objetivos possam ser compartilhados e os desafios divididos em uma equipe.

O modelo de avaliação aqui proposto utilizou um sistema de pontuação de 1 a 5 , em que a escala de avaliação se apresenta da seguinte forma: péssimo (1), ruim (2), regular (3), bom (4) e excelente (5). No total, quatro pesquisadores avaliaram separadamente o jogo de acordo com esses critérios e sistema de pontuação. Além da pontuação, cada pesquisador definiu uma justificativa para a pontuação conferida a cada critério, auxiliando na compreensão da avaliação individual. A pontuação final atribuída ao jogo em cada critério foi definida através da média aritmética, ou seja, a soma de todas as pontuações atribuídas por cada um dos avaliadores para um determinado critério dividida pelo número total de avaliadores. Os critérios e os resultados são apresentados na seção Resultados Obtidos e Discussões.

\subsection{Avaliação Formativa}

A avaliação formativa foi realizada em duas escolas da rede privada, utilizando computadores de mesa no laboratório de informática, e no ambiente domiciliar, utilizando tablets. Foram alcançadas 39 crianças cujas idades variavam entre cinco e sete anos de idade, oriundas do $1^{\circ}$ ou $2^{\circ}$ ano do Ensino Fundamental. Os responsáveis foram notificados e assinaram termos de consentimento, permitindo a participação e os registros fotográficos.

No âmbito escolar, a atividade avaliativa transcorreu enquanto atividade da aula de informática. Neste sentido, as crianças foram convidadas a jogar The Foos como atividade do dia, com tempo estimado entre 20 (Escola A) e 30 minutos (Escola B). Inicialmente, foi proposto que as crianças jogassem e solicitassem ajuda sempre que sentissem necessidade, de modo que sempre que necessário foram fornecidas instruções que auxiliassem as crianças na compreensão de alguns elementos. As observações e anotações qualitativas foram tomadas por uma das pesquisadoras, que se manteve circulando pela sala sem interagir com as crianças, no entanto lhes foi apresentada inicialmente, a fim de evitar estranhamento ou perturbação por parte das crianças.

No âmbito domiciliar, três crianças, do círculo de relacionamento de uma das pesquisadoras, foram abordadas em suas residências, com o acompanhamento da pesquisadora tomando nota do desempenho e com a presença dos responsáveis. Foi proposto que as crianças jogassem individualmente e sem tempo estimado para término. Em se tratando do ambiente familiar, notou-se que as crianças pediram ajuda mais rapidamente, e quase sempre eram respondidas com outra pergunta que as incitava a repensar e tentar outra vez. 


\section{Resultados Obtidos e Discussões}

A avaliação objetiva teve 5 dos 10 critérios considerados bons, outros 3 foram considerados excelentes, e apenas 1 foi considerado regular (Figura 1). A facilidade de uso foi avaliada como boa, pois a interação do usuário com o sistema acontece de forma intuitiva, porém existem algumas funções em que o usuário precisa de mais informações para poder fazer uso corretamente. O design de tela também foi considerado bom, com um gráfico agradável e fontes de fácil reconhecimento, apesar de alguns itens apresentarem uma dificuldade em comunicar sua funcionalidade.

A apresentação da informação foi avaliada como regular. Considera-se que este seja o aspecto no qual o programa precisa investir mais, pois existe a dificuldade em encontrar algumas das informações básicas do jogo. A afetividade foi avaliada como excelente, pelo jogo possuir um ambiente bem atrativo e uma proposta bem divertida, com muitas cores e personagens que se movimentam e dançam quando o usuário toca na tela, o que fomenta uma maior interação entre o usuário e o software.

A objetividade foi avaliada como boa. Inicialmente o usuário é guiado para selecionar as ferramentas corretas para atingir a meta do jogo através de recursos visuais, mas com o avanço do jogo esse suporte acaba não acontecendo como no início. A motivação foi mais um aspecto considerado bom, pois o jogo possui um sistema tradicional de pontuação, e níveis e atalhos desbloqueados ao passar das fases.

A estruturação foi avaliada como excelente, pois o jogo possui uma sequência bem definida e clara. O controle do aluno também foi considerado excelente, uma vez que o usuário assume autonomia no decorrer do jogo, podendo determinar quais ferramentas pretende utilizar e qual dos níveis desbloqueados pretende jogar novamente a fim de conseguir uma melhor pontuação. O último critério, aprendizado cooperativo, não foi avaliado por ter sido considerado um jogo individual e por não ter sido observado nenhum tipo de opção que permitisse a cooperação e interação no jogo.

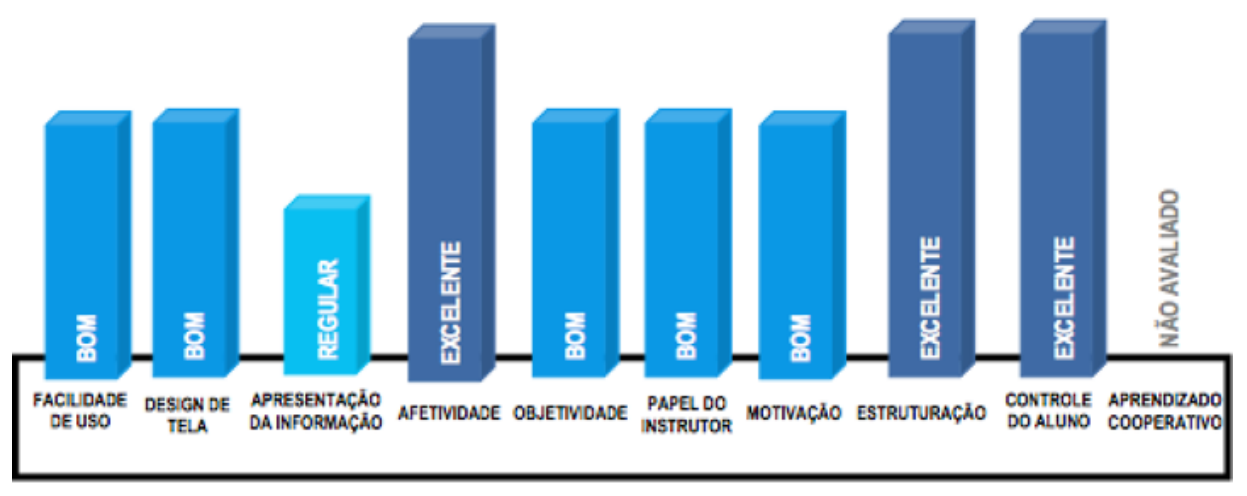

Figura 1. Resultados da Avaliação Objetiva

Já a avaliação formativa permitiu observar aspectos que abrangem desde a motivação das crianças ao longo do jogo, até mesmo a compreensão de elementos da interface e a compreensão de alguns conceitos elementares associados ao pensamento computacional. As crianças demonstraram um envolvimento intenso com o jogo, mesmo diante de desafios para os quais elas não conseguiram desenvolver a solução de imediato. Comumente, quando as crianças se deparam com situações nos jogos em que elas não conseguem avançar com facilidade, a maioria delas solicita mudar de jogo sob 


\section{CBIE-LACLO 2015}

Anais dos Workshops do IV Congresso Brasileiro de Informática na Educação (CBIE 2015)

a premissa de que o jogo é chato, quando na verdade querem expressar que consideram o jogo difícil. E, embora as crianças expressassem que achavam o jogo chato nos momentos em que se depararam com atividades mais difíceis, não solicitaram mudar de jogo.

Convém mencionar ainda que embora tenha havido intervalos de tempo diferentes destinados ao uso dos jogos pelas crianças, este aspecto não foi relevante em relação ao desempenho obtido. No entanto, foi possível observar que as crianças mais velhas eram mais criteriosas ao construir as instruções, tendo o cuidado em colocar o mínimo de blocos de comando possíveis.

No caso do The Foos a dificuldade é acrescida gradualmente e à medida que novos conceitos são apresentados, eles são reforçados no nível seguinte. Isto permite às crianças um tempo razoável de assimilação além de reforçar a prática apreendida no nível anterior. Os elementos da interface foram, de um modo geral, compreendidos com facilidade.

Um aspecto problemático, no entanto, deu-se quanto à execução dos comandos e quanto à mudança de direção. No tocante à execução de comandos, as crianças costumavam arrastar os blocos para o painel de execução, no entanto, não foi intuitivo para elas clicarem no personagem para que a execução pudesse ser iniciada. Adicionalmente, o personagem só executava os comandos se as crianças clicassem no centro do personagem, cliques ou toques nas extremidades, como, por exemplo, no chapéu do personagem não surtiam qualquer efeito e não geravam nenhuma mensagem de erro, de modo que as crianças ou ficavam esperando alguma ação ou clicavam várias vezes até que o personagem se movesse (Figura 2).

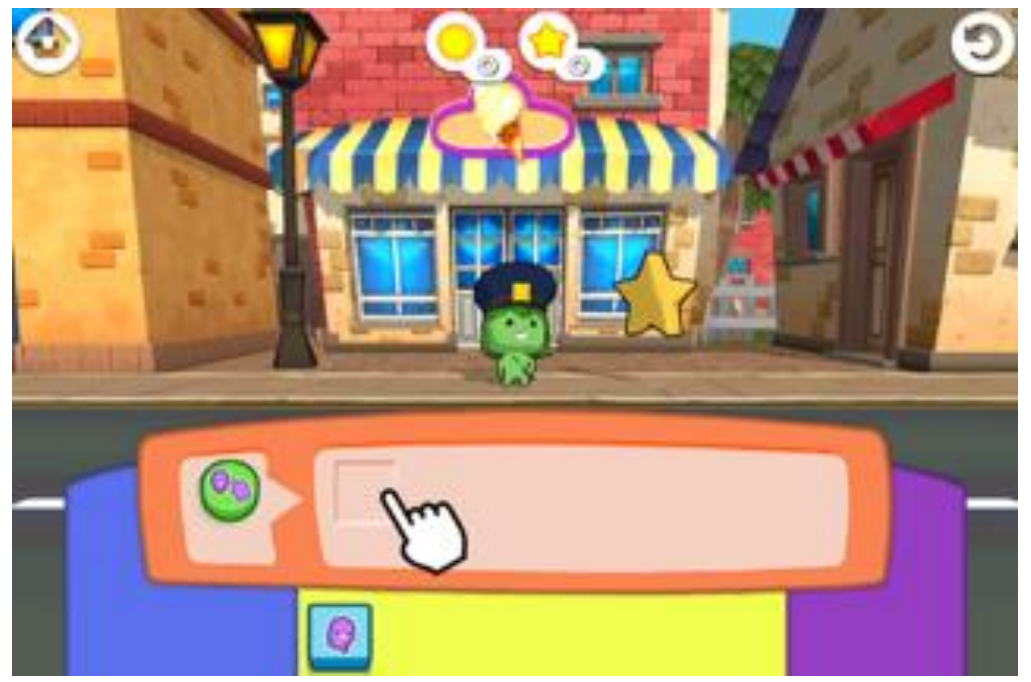

Figura 2. Fase 1 do The Foos

No que tange à mudança de direção do personagem, era necessário clicar no botão de comando que faz com que o personagem ande para que seja possível selecionar a seta direcional para esquerda ou para direita (Figura 3). 


\section{CBIE-LACLO 2015}

Anais dos Workshops do IV Congresso Brasileiro de Informática na Educação (CBIE 2015)

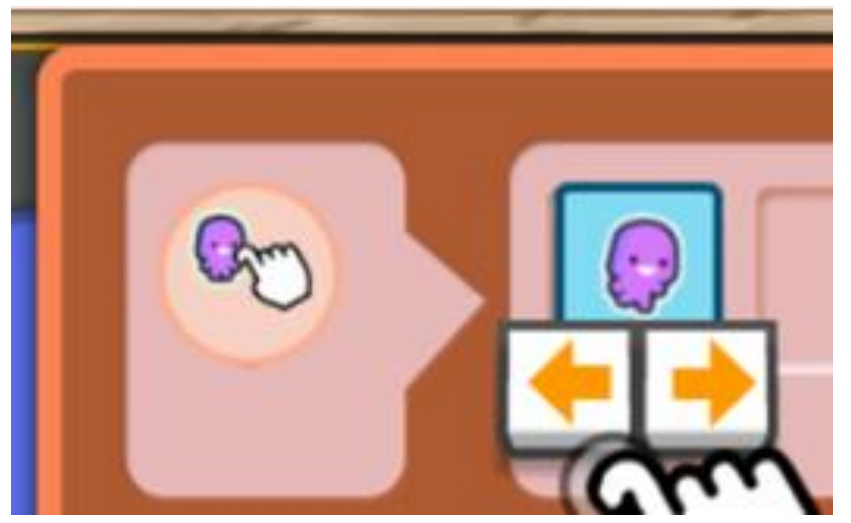

Figura 3. Escolha da direção para onde o personagem deve andar

Convém mencionar que o jogo se propõe a apresentar os seguintes conceitos: Lógica, Sequenciamento, Reconhecimento de Padrões, Controle de Fluxo, Pensamento Algorítmico e Solução de Problemas [Code Spark 2015]. Em particular no que se refere ao Controle de Fluxo, foi percebido que o subconceito que demonstrou ser menos compreendido foi o de repetição.

Inicialmente, espera-se que a criança identifique um padrão de ações que se repete e posteriormente acione um comando que repita um determinado conjunto de ações. Na fase que antecede a apresentação do botão de comando que representa a repetição, uma série de barris são lançados contra o personagem que deve ultrapassá-los apenas pulando repetidamente até alcançar a estrela (Figura 4).

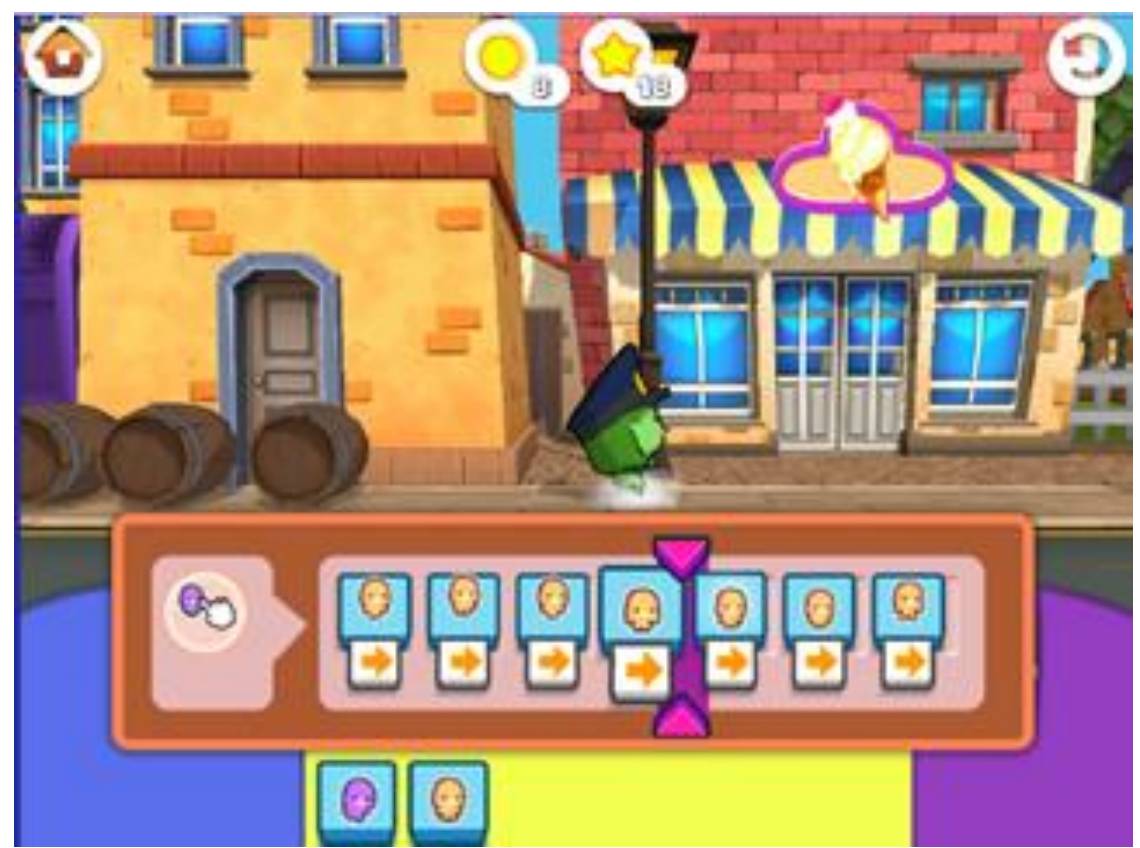

Figura 4. Fase em que as crianças necessitam pular os barris

Aparentemente, o objetivo desta fase é deixar explícita a necessidade de um comando que permita repetir ações diversas, inserindo assim o que seria uma possibilidade para o uso do comando de repetição. Entretanto este objetivo não foi alcançado, pois nas fases subsequentes as crianças ou não utilizavam o comando de 
repetição, ou quando o utilizavam não compreendiam sua funcionalidade, sobretudo no que se refere ao parâmetro que definia a quantidade de repetições.

\section{Comparação dos Resultados das Avaliações Formativa e Objetiva}

De um modo geral, ambas avaliações foram muito similares quanto aos resultados encontrados. Durante a avaliação formativa, por exemplo, constatou-se que as crianças não tiveram dificuldades em interagir com o jogo e os personagens, excetuando-se algumas questões como, por exemplo, a já citada dificuldade em clicar/tocar no personagem para iniciar a execução, uma vez que esta ação só funcionava quando as crianças clicavam/tocavam no centro do personagem.

As representações gráficas da interface foram, em sua maioria, adequadas e facilmente reconhecidas, salvo alguns blocos e/ou funcionalidades muito específicas como a mudança de direção demonstrada na Figura 3. De maneira ampla, estes resultados foram convergentes com a avaliação dada aos critérios facilidade de uso e design de tela.

Considerando o critério de apresentação da informação, considerada regular na avaliação objetiva, observou-se que os resultados em ambas avaliações foram similares. Muito embora não haja configurações a serem feitas e o jogo disponha da instrução de uma mão que indica quais as principais ações a serem realizadas, não é possível encontrar uma opção de ajuda. Ou seja, não há opções que indiquem, por exemplo, qual o objetivo da fase em questão, ou que permitam visualizar a resolução da tarefa, o que evoca a necessidade do acompanhamento de um responsável para auxiliar a criança.

Similarmente, quanto aos critérios de afetividade e motivação, os resultados obtidos com a avaliação objetiva confirmaram-se na avaliação formativa, uma vez que as crianças demonstraram intenso envolvimento emocional com o jogo, além de terem se mantido engajadas durante a realização das atividades durante todo o tempo estimado.

No entanto, quanto ao critério de objetividade classificado com "Bom", os resultados obtidos com a avaliação formativa divergiram da avaliação objetiva. Embora uma mão induza o usuário para a realização das tarefas, nos níveis mais avançados as crianças acabam por apenas repetir a ação proposta pela mão, sem compreender o que estão realizando. Aparentemente o objetivo da fase em questão não lhes parece claro, de tal modo que nas fases subsequentes, ao se depararem com desafios similares, elas não conseguem solucionar o problema utilizando os conceitos que deveriam ter sido apreendidos na fase imediatamente anterior.

Quanto à estruturação, como o jogo é sequencialmente bem definido e não é permitido às crianças avançarem para outras fases sem terem concluído fases anteriores, isto as impede de alcançar fases que utilizem conceitos que ainda não lhes foram apresentados, algo que se mostrou importante ao longo da avaliação formativa.

No que tange ao critério controle do aluno, pode-se observar uma situação sutilmente dessemelhante durante a avaliação formativa. Embora os alunos possam retomar níveis anteriores e realizar experimentação criativa das funcionalidades de cada personagem em fases bônus, o percurso é totalmente definido. Deste modo, devido à sua característica altamente estruturada, todos os alunos só poderão trilhar os mesmos 
percursos sequenciais de aprendizagem no jogo, variando apenas as possibilidades de experimentação, ou seja, não há adaptabilidade ao aluno.

\section{Considerações Finais}

Com as duas avaliações tornou-se possível a observação de diferentes aspectos referentes ao jogo The Foos e sua forma de ensino do pensamento computacional para crianças. Enquanto com a avaliação formativa, foi possível avaliar especificamente a resposta do público-alvo em relação às funcionalidades do jogo, na avaliação objetiva foi feita uma análise do jogo de acordo com 10 parâmetros que abordaram vários critérios de avaliação que vão desde facilidade de uso até mesmo afetividade e motivação.

$\mathrm{Na}$ avaliação formativa, foram observadas dificuldades das crianças com o jogo (por exemplo, as fases mais problemáticas), e quais funcionalidades desenvolvidas para ajudar o usuário não conseguiram atingir o público-alvo (como instruções oferecidas pela animação da mão, em especial quando se tratava de realizar ações novas).

Foi observada a diferença na interação das crianças com o jogo de acordo com a plataforma utilizada, quando ao não entender a ajuda que a mão estava indicando, as crianças que utilizaram o tablet tenderam a tocar na tela sem parar para pensar no que deveriam fazer, apenas esperando que algo acontecesse.

Nos momentos em que as crianças sentiram dificuldades elas pediram ajuda. Comumente isto ocorria na realização de atividades com muitas tarefas, mas os momentos realmente mais críticos para o entendimento foram as apresentações de blocos de lógica mais avançados. Essa necessidade apenas evidencia que o sistema de ajuda do jogo não é suficiente e torna claro que para um melhor aproveitamento é necessária a presença de um professor que explane os conceitos de lógica associados aos blocos (alguns desses conceitos são apresentados mas não inteiramente compreendidos pelas crianças).

Adicionalmente o jogo The Foos surpreendeu quanto a algumas falhas básicas que poderiam ser facilmente identificadas pelo time de desenvolvimento com uma avaliação como as realizadas neste trabalho. Outros resultados relevantes poderiam ser obtidos através da comparação com outros softwares de mesmo objetivo.

\section{Referências}

Brito Junior, O. O. (2014) "Estudo comparativo entre abordagens metodológicas para avaliação objetiva de softwares educativos." Trabalho de conclusão de curso de Licenciatura em Ciências da Computação, UFPB.

Code Spark (2015) The Foos, thefoos.com/, Julho.

Campos, G. H. B. (1989) “Construção e validação de ficha de avaliação de produtos educacionais para microcomputadores.” Dissertação de Mestrado - Faculdade de Educação, Universidade Federal do Rio de Janeiro.

Gladcheff, A. P., Zuffi, E. M. e Silva, M. D. (2011) "Um Instrumento para Avaliação da Qualidade de Softwares Educacionais de Matemática para o Ensino Fundamental". VII Workshop de Informática na Escola, Fortaleza-CE. 
Nesbit, J., Belfer, K., Leacock, T. (2002) Learning Object Review Instrument (LORI), http://cenlinu1.centennialcollege.ca/aahs/LORI/help.php, Junho.

Nicoletti, A. A. M. e Filho, R. R. G. (2004). “Aprender brincando: a utilização de jogos, brinquedos e brincadeiras como recurso pedagógico." Revista de divulgação técnicocientifica do ICPG, v.2, n.5 p.91-94.

Oliveira, C. C., Costa, J. W. e Moreira, M. (2001) "Ambientes informatizados de aprendizagem." Produção e Avaliação de Software Educativo. Campinas: Papirus.

Rocha, A. R. C. (1987) “Análise e Projeto Estruturado de Sistemas.” Rio de Janeiro, Campus.

Schneider, H. N. (2002) "Um ambiente Ergonômico de Ensino-Aprendizagem Informatizado", Tese (Doutorado em Engenharia de Produção) - Universidade Federal de Santa Catarina.

Von Wangenheim, C. G. e Von Wangenheim, A. (2012) "Ensinando Computação com Jogos". Bookess.

Von Wangenheim, C. G., Nunes, V. R., Santos, G. D., Alves, N. C., Coan, E. S. e Mansur, C. (2014) "Resumo de Objetivos de Aprendizagem de Computação no Ensino Fundamental (Currículo de Referência CSTA/ACM K-12)", http://bit.ly/1AEXLrc, Maio 